Tradução 


\section{Transformando o círculo interno: o desafio de Dorothy Smith à teoria sociológica ${ }^{* 1}$}

\section{Transforming the Inner Circle: Dorothy Smith's Challenge to Sociological Theory}

DOI:10.12957/ek.2019.48674

Dra. Patricia Hill Collinss ${ }^{* 2}$ collinph@umd.edu

Universidade de Maryland [EUA]
Tradução Ms. Raquel Suely Cardoso da Conceição*3 raquelsuelyc@gmail.com Universidade Federal de São Paulo [UNIFESP]

Revisão da Tradução Deborah Moreira Guimarães ${ }^{* 4}$ Marjorie Nogueira Chaves*5

Recentemente, as traduções para o português das produções de mulheres negras da diáspora têm ganhado maior relevância em periódicos e editoras nacionais. Essa mudança de enfoque responde ao crescente interesse acadêmico por discussões que proponham uma análise crítica dos paradigmas hegemônicos das ciências sociais sob um olhar feminista. No presente artigo, Collins busca elucidar a perspectiva crítica de Dorothy Smith sobre a produção da sociologia contemporânea, apontando as suas contradições. As autoras destacam os limites do círculo interno da teoria sociológica, indicando esse lugar como de exclusão de grupos historicamente marginalizados. Lançam o desafio da construção de novos ângulos de visão que transcendam o discurso dominante a partir da experiência das mulheres no campo da sociologia.

\footnotetext{
*1 Artigo originalmente publicado pela American Sociological Association, Vol. 10, №. 1 (Spring, 1992), p. 73-80. Agradecemos à professora Patricia Hill Collins a gentileza e a atenção no processo de solicitação dos direitos autorais deste artigo, sobretudo, por ter providenciado generosamente os recursos que viabilizaram a autorização de republicação neste dossiê.

*2 É professora do Departamento de Sociologia da Universidade de Maryland (Estados Unidos) e ex-presidenta do Conselho da Associação Americana de Sociologia (ASA); autora de vários livros sobre pensamento feminista negro, entre eles: Black Feminist Thought e Knowledge, Consciousness and the Politics of Empowerment.

*3 É bacharela e mestra em Ciências Sociais pela UNIFESP. Dedica-se a estudar as dinâmicas de gênero, raça e classe, e seus efeitos na formação das identidades, com base na tradição do Pensamento Feminista Negro.

*4 É mestre e doutora em Filosofia pela UNIFESP. Pesquisa temas relacionados à fenomenologia e à hermenêutica, sobretudo, no escopo da filosofia contemporânea.

*5 É mestra em História e doutoranda em Política Social pela UnB. Graduada em História pela União Pioneira de Integração Social. É pesquisadora do Núcleo de Estudos Afro-Brasileiros e vice coordenadora do Observatório da Saúde da População Negra.
} 
Recently, translations into Portuguese of the productions of black women from the diaspora have gained greater relevance in national journals and publishers. This change in focus responds to the growing academic interest in discussions that propose a critical analysis of the hegemonic paradigms of the social sciences under a feminist perspective. In this article, Collins seeks to elucidate Dorothy Smith's critical perspective on the production of contemporary sociology, pointing out its contradictions. The authors highlight the limits of the inner circle of sociological theory, indicating this place as an exclusion of historically marginalized groups. They pose the challenge of building new angles of vision that transcend the dominant discourse from the experience of women in the field of sociology.

\section{KEYWORDS Women. Outsider-within. Sociological Theory. Inner circle. Domination}


Transformando o Círculo Interno: o Desafio de Dorothy Smith à Teoria Sociológica
Dra. Patricia Hill Collins [UMD - EUA] tradução: Ms. Raquel

Suely Cardoso da

Conceição [UNIFESP]

"As mulheres têm sido amplamente excluídas do trabalho de produção de formas de pensamento e das imagens e símbolos nos quais o pensamento é expresso e ordenado", sugere a socióloga Dorothy E. Smith. "Nós podemos imaginar a exclusão das mulheres como se fosse organizada pela formação de um círculo entre homens, que somente atendem e consideram significativo o que eles mesmos dizem." Nesse discurso masculino, "o que homens faziam era relevante para homens, era escrito por homens, sobre homens e para homens... é assim que uma tradição é formada" (Smith, 1987, p. 18). A perspectiva de Smith descreve, de maneira apropriada, o círculo externo que delimita a sociologia de outras disciplinas igualmente centralizadas nos homens, mas, ela também caracteriza o importante círculo interno da teoria sociológica situada no centro desse campo.

Em um mundo estruturalista, onde sociólogos almejavam desenvolver teorias científicas que explicassem uma realidade ostensivamente objetiva, o círculo interno da teoria sociológica era tão seguro que seus participantes tinham pouca necessidade de se protegerem. Tal como membros de um time de futebol americano, encarando uns aos outros entre jogadas, falando em códigos que só os jogadores do time podem entender, os membros do círculo interno sentiam-se livres para falar somente entre si sobre coisas de seu próprio interesse, como insiders. Enquanto defensores do núcleo de sociologia como uma ciência, eles eram protegidos pelas subespecialidades balcanizadas ${ }^{1}$, ocupando o terreno sociológico remanescente. Tais subespecialidades recebiam grande consideração devido à sua proximidade com o círculo interno tangenciado ao núcleo teórico, enquanto os outros, próximos às margens depreciadas, suportavam o peso da manutenção das fronteiras do círculo externo.

No entanto, em um mundo cada vez mais pós-estruturalista, interpretações sociológicas positivistas da realidade social têm sido fortemente desafiadas por pessoas de cor, mulheres, gays e lésbicas, e outros grupos historicamente marginalizados. A partir de suas perspectivas, as alegações de que a sociologia seria uma ciência objetiva e de valor neutro soam falsas. Para eles, tradições sociológicas produzidas por um círculo homogêneo de integrantes (insiders) representam uma perspectiva parcial sobre as relações sociais. Raça, classe, gênero e heterosexismo agora apresentam desafios maiores ao campo como um todo. Porém, apesar dessas mudanças significativas, o círculo interno da teoria socio-

1 N.T.: O termo, pouco utilizado na língua portuguesa, pode ser definido como a fragmentação de uma unidade política (país ou região) em unidades menores. No texto, o termo refere-se ao caráter fragmentado e mutuamente hostil das subespecialidades da sociologia, criticado por Dorothy Smith. 
Transformando o Círculo Interno: o Desafio de Dorothy Smith à Teoria Sociológica
Dra. Patricia Hill Collins [UMD - EUA] tradução: Ms. Raquel

Suely Cardoso da

Conceição [UNIFESP]

lógica - seus membros, sua epistemologia e suas abordagens teóricas - permanece estranhamente intocado pelas mudanças que afetam o restante da disciplina.

Em seus 20 anos de pesquisa publicada, recentemente compiladas em três coletâneas de ensaios, Dorothy E. Smith (1987, 1990a, 1990b) tem desafiado consistentemente a esmagadora participação masculina e branca do círculo interno da sociologia, visando tanto a sua maneira de fazer teoria sociológica quanto as teorias que eles têm produzido. Dois temas abrangentes guiaram seu trabalho. Primeiro, Smith investigou a organização social do conhecimento objetificado a fim de demonstrar como tal conhecimento constitui, para o capitalismo contemporâneo, uma parte essencial das relações de dominação. A sociologia representa um exemplo desse tipo de conhecimento objetificado. Em The Conceptual Practices of Power: A Feminist Sociology of Knowledge e em Texts, Facts, and Femininity: Exploring the Relations of Ruling (daqui em diante chamado de Conceptual Practices and Texts), Smith analisa a centralidade das ideias e do conhecimento nos processos de dominação dentro do capitalismo contemporâneo.

Segundo, Smith procurou explorar o social a partir do lugar de experiências das mulheres. Em seus dois ensaios inovadores, "A Peculiar Eclipsing: Women's exclusion from Man's Culture" e "A Sociology for Women", ambos escritos entre 1972 e 1977 e publicados em versão revisada em The Everyday World as Problematic (daqui em diante chamado de Everyday World), Smith apresenta a estrutura que orienta seu trabalho posterior. Ao utilizar o ponto de vista das mulheres para desafiar o conhecimento centrado no masculino, Smith visa desenvolver uma sociologia na qual a problemática do mundo cotidiano se torna o foco de investigação. Seu objetivo é produzir uma sociologia para mulheres, não sobre mulheres. "Suponha, então, que nós comecemos a conceber uma iniciativa sociológica que não seja direcionada primariamente para o discurso e àquele que o conhece, mas capaz de produzir uma sociologia para mulheres", afirma Smith. Questões surgiriam a partir do conhecimento cotidiano da sociologia, não de seu [conhecimento] objetificado. "Poderíamos tentar desenvolver para mulheres, análises, descrições e compreensões de sua situação, de seu mundo cotidiano e de suas determinações na organização socioeconômica mais ampla à qual está articulada” (Smith 1987, p. 88).

O trabalho de Dorothy Smith desafia profundamente a santidade do círculo interno da teoria sociológica. Desenvolver uma sociologia para mulheres significa não mais aceitar como prática sociológica que homens conversem entre si sobre o que eles julgam importante. Enxergar a sociologia não como uma ciên- 
Transformando o Círculo Interno: o Desafio de Dorothy Smith à Teoria Sociológica
Dra. Patricia Hill Collins [UMD - EUA]

cia da sociedade, mas como uma parte importante das relações de dominação dentro do capitalismo contemporâneo, certamente, questiona quem pertence ao círculo interno e de quem são os interesses representados nas teorias produzidas pelo círculo. Agora que sua segurança como intérpretes teóricos de uma realidade "fixa" é cada vez mais questionada, membros do círculo interno não podem mais virar suas costas para Dorothy Smith e outras reclamantes. Talvez seja o momento de esses indivíduos pararem de ouvir apenas uns aos outros e alguns poucos escolhidos a dedo que conseguem penetrar em suas fileiras. Se o círculo interno deve ser transformado, de quais modos o trabalho de Dorothy Smith desafia a teoria sociológica existente? Mais importante, o trabalho de Dorothy Smith nos levará aonde queremos ir?

\section{Os desafios de Dorothy Smith à teoria sociológica}

O trabalho de Dorothy Smith oferece uma série de desafios importantes para a tarefa de transformar o círculo interno da sociologia. Primeiro, ao fundamentar seu trabalho nas teorias sociológicas e, simultaneamente, recusar-se a adotar, de maneira completa, qualquer perspectiva teórica, Smith fornece o modelo do processo complicado de utilização daquilo que é melhor nas tradições sociológicas para questionar a própria noção de tradição sociológica. "Eu não sou uma interacionista simbólica, nem uma socióloga fenomenológica, nem uma socióloga Marxista, tampouco uma etnometodóloga", ela escreve. "A estratégia sociológica que tenho desenvolvido não pertence e nem se sujeita aos procedimentos interpretativos de qualquer escola interpretativa da sociologia" (1987, p. 9). A recusa de Smith em fundamentar completamente seu trabalho em qualquer abordagem lhe permite evitar a armadilha comum de se enraizar com tanta firmeza em uma especialidade teórica, de modo que suas nuances se tornam o foco de investigação. Em grande parte de seu trabalho, ela mantém uma posição crítica sobre o conhecimento sociológico, enquanto utiliza o melhor desse conhecimento ${ }^{2}$.

O ecletismo de Smith claramente enriquece seu trabalho. Primeiro, em Conceptual Practices, sua discussão sobre a organização social da realidade textual

2 Em meu próprio trabalho eu me refiro a essa posição como aquela de um "outsider within", que fornece uma nova perspectiva sobre o conhecimento interno como conhecimento objetificado da sociologia (Collins, 1990). Porque Smith é uma mulher em uma comunidade de homens, ela nunca poderá ser aceita como uma deles, porque ela nunca poderá ser uma deles. Seu posicionamento sobre a "line of fault" entre a sociologia e suas experiências enquanto uma mulher cria uma posição outsider-within, que pode formar a base de uma consciência crítica. 
Transformando o Círculo Interno: o Desafio de Dorothy Smith à Teoria Sociológica
Dra. Patricia Hill Collins [UMD - EUA] tradução: Ms. Raquel

Suely Cardoso da

Conceição [UNIFESP]

assemelha-se à análise de Marx sobre a organização social das relações de mercado. Smith rejeita a perspectiva sociológica convencional de que as relações sociais consistem em relacionamentos fixos entre status ou papéis em um ponto no tempo. Ao contrário, ela considera as relações sociais como a organização de sequências de ações no tempo. As investigações não podem ser restritas às relações com as quais Marx estava primeiramente preocupado, a saber, a economia. O mundo de Marx estava apenas começando a fazer uso de textos como essenciais às relações de dominação dentro do capitalismo, ao passo que "somos parte de um mundo, um segmento maior da organização, que é mediado por textos" (SMITH, 1990b, p. 160). Smith adota a estratégia de Marx de observar os processos sociais como atividades em curso de pessoas reais, e a estende aos fenômenos que, anteriormente, eram tratados como subjetivos ou culturais. Utilizando a metodologia de Marx de examinar as relações de mercado dentro do capitalismo inicial, Smith investiga o discurso e a ideologia como relações sociais essenciais ao capitalismo contemporâneo. Dessa maneira, ela recupera muitos dos princípios norteadores da metodologia Marxista a partir das estruturas positivistas que influenciam a teorização marxista recente ${ }^{3}$.

Segundo, o trabalho de Smith consegue atravessar o hiato entre as abordagens sociológicas objetivistas e as [abordagens sociológicas] construtivistas da sociedade, uma distinção frequentemente mascarada pela divisão entre a macro e a microssociologia. "O efeito de localizar o intelectual no mundo cotidiano da experiência atrai para dentro de uma determinada relação aquilo que nós conhecemos como os níveis ‘microssociológico' e ‘macrossociológico' do mundo cotidiano, os quais nós tornamos observáveis como 'elites de poder', 'organização formal', 'estratificação' e o ‘estado"”, observa Smith (1987, p. 99). Seu trabalho empírico mostra o valor de localizar intelectuais no mundo cotidiano e questionar como o seu conhecimento é organizado. Em seu intrigante ensaio "Femininity as Discourse", por exemplo, Smith examina a construção social do gênero "atentando-se às especificidades, não ao gênero de maneira abstrata, não como algo total, mas múltiplo e, às vezes, de relações contraditórias” (1990b, p. 159).

Terceiro, ao se basear em muitos dos princípios norteadores da pesquisa feminista, Smith demonstra a importância de observar para além das tradições

3 Tanto Texts quanto Conceptual Practices contêm capítulos nos quais Smith demonstra como as abordagens etnometodológicas podem ser utilizadas para examinar as conexões entre o conhecimento e as relações de dominação. Eu consigo entender por que Smith considera tais abordagens úteis no estudo do processo dinâmico das construções sociais. Entretanto, sua escolha do tema em vários de seus ensaios, como "The Social Organization of Subjectivity: An Analysis of the Micro-Politics of a Meeting" " "The Active Text: A Textual Analysis of the Social Relations of Public Textual Discourse" (1990b), provavelmente irá interessar, sobretudo, a especialistas. 
Transformando o Círculo Interno: o Desafio de Dorothy Smith à Teoria Sociológica
Dra. Patricia Hill Collins [UMD - EUA] tradução: Ms. Raquel

Suely Cardoso da

Conceição [UNIFESP]

sociológicas como uma forma de revitalizar o discurso sociológico. Por exemplo, a teoria feminista postula que um caminho para a compreensão do generalizável é encontrado no exame de experiências concretas, um princípio exemplificado pelo popular slogan feminista "O pessoal é político". Smith identifica a necessidade de um novo ponto de partida para a sociologia, enraizado nas experiências reais das pessoas à medida que elas seguem suas vidas, em vez de em construções ideológicas da teoria herdada das tradições sociológicas. Em “Women's Experience as a Radical Critique of Sociology”, Smith (1990a) argumenta que a sociologia permanece incapaz de analisar suas relações para com suas condições sociais subjacentes porque seus procedimentos objetificam e separam as pessoas de seu conhecimento.

Uma maneira pela qual os homens têm dominado é convencendo os grupos subordinados de que o conhecimento centrado no masculino é universal e científico, e de que as formas de conhecer das mulheres são concretas, personalizadas e, de alguma forma, menos válidas. Construir uma sociologia para mulheres não evita o exame da posição das mulheres; a transformação sociológica precisa assumir uma postura similar. "O intelectual sociólogo, portanto, não é o sociólogo enquanto tal", Smith observa. "O trabalho do sociólogo é desenvolver uma sociologia capaz de explicar para os membros da sociedade a organização social de seu mundo experienciado, incluindo nessa experiência as maneiras pelas quais ela transcende ao que é imediata e diretamente conhecido" (1987, p. 89).

O quarto desafio de Smith é ampliar a nossa compreensão do modo como a dominação opera por meio da organização do conhecimento. Suas análises abrangentes sobre o papel da sociologia no fortalecimento das relações de dominação são, especialmente, pertinentes (1989b, 1990a). "Se a sociologia não pode evitar de ser situada", ela reivindica, "então ela deveria tomar isso como seu começo e construí-lo no interior de suas estratégias metodológicas e teoréticas" (1990a, p. 22). Smith torna visível o que é, geralmente, apresentado como invisível na sociologia: a objetificação de seres humanos e a organização do campo baseada em gênero. Ao argumentar que as práticas sociológicas de pensamento e escrita convertem as experiências concretas das pessoas enquanto sujeitos em conhecimento objetificado, Smith (1989b, 1980a) salienta a necessidade de novas aproximações com a teorização sociológica e oferece estratégias alternativas provocativas. Ela examina como o pensamento sociológico objetifica a experiência. "Começar com as formulações teóricas da disciplina e interpretar as realidades das atividades das pessoas como expressões do já dado é criar ideologia, não conhecimento" (1990a, p. 48). Enquanto as definições existentes de ideologia enfatizam sua função como um corpo de ideias 
Transformando o Círculo Interno: o Desafio de Dorothy Smith à Teoria Sociológica
Dra. Patricia Hill Collins [UMD - EUA] tradução: Ms. Raquel

Suely Cardoso da

Conceição [UNIFESP]

ou conceitos, Smith vê a ideologia como um método de raciocínio pelo qual as práticas de pessoas reais são convertidas em um espaço atemporal e deslocado, que consiste em mera linguagem, rotulada "conhecimento". Smith afirma que o discurso sociológico de todas as convicções teóricas oblitera a experiência vivida. "Textos" ou escritos sociológicos constituem os artefatos para a análise da organização social do conhecimento.

Smith explora as conexões entre textos e relações de dominação usando um método de desconstrução textual que difere a abordagem atemporal e ahistórica de algumas abordagens pós-modernistas. Suas discussões sobre "facticidade" e "tempo textual" são especialmente inovadoras. Fatos não são nem afirmações em si mesmas, nem as realidades às quais as afirmações se referem. Em vez disso, fatos são uma organização de práticas de inscrição de uma realidade em um texto para que aprendamos a ver a realidade nos termos dos, assim chamados, fatos. "O momento inicial do processo textual é aquele ponto crucial no qual muitos, quando não, todo e qualquer vestígio do que ocorreu, quando isso foi levado em conta, é apagado, e o que resta é apenas o texto, cujo propósito é ser lido como 'o que realmente aconteceu /o que é"' (Smith, 1990a, p. 79). Smith avança para examinar como as relações de dominação subjacentes determinam a facticidade ou as "superfícies factuais" dos textos. Ao investigar a separação entre as experiências dos sujeitos e a construção de suas histórias de casos por aqueles em posições de autoridade, Smith, engenhosamente, ilumina as conexões entre textos e poder. Discursos ideológicos, como a sociologia, protegem o aparelho dominante das disjunções entre "as realidades das vidas das pessoas" e as representações ideológicas do mundo, produzidas pelas estruturas dominantes.

Em uma quinta linha de desafio, Smith tenta curar a separação problemática entre trabalho sociológico teórico e empírico. Ela desenvolve sua dupla ênfase temática investigando como o conhecimento é essencial para comandar e criar uma sociologia para mulheres, não exclusivamente por meio da teorização de gabinete, mas também por meio do trabalho empírico que testa essas ideias principais e, por sua vez, é moldado por elas. Por exemplo, o Conceptual Practices contém estudos de casos que ilustram como as análises sociológicas da organização social do conhecimento podem ser conduzidas. Um desses estudos diz respeito à realidade textual dos dados estatísticos utilizados na mensuração das chamadas doenças mentais e analisa como os indivíduos que escrevem relatos de casos sobre aqueles que procuram serviços psiquiátricos constroem a facticidade da doença mental. Por meio de uma análise detalhada do tratamento da morte de uma mulher em um texto, outro estudo mostra como os textos constroem a nossa compreensão do evento. Smith utiliza esses casos para ilus- 
Transformando o Círculo Interno: o Desafio de Dorothy Smith à Teoria Sociológica
Dra. Patricia Hill Collins [UMD - EUA] tradução: Ms. Raquel

Suely Cardoso da

Conceição [UNIFESP]

trar uma sociologia do conhecimento alternativa. Esse confronto é espelhado em capítulos de Texts, que tratam da análise da micropolítica de um encontro, com o uso de textos na estruturação de percepções da ação policial e, em uma excelente discussão no "Femininity as Discourse", que tratam da forma como as revistas e a mídia popular são centrais na construção social da feminilidade.

De modo geral, o trabalho de Dorothy Smith aponta a necessidade de um novo ponto de partida na sociologia, enquanto também identifica problemas no interior da disciplina que trabalha contra um novo início. Os desafios de Smith para o círculo interno são evidentes - mas o seu pensamento nos levará aonde queremos ir?

\section{Transformando o círculo interno}

A crítica é um primeiro passo vital na desconstrução do conhecimento objetificado que é essencial para as relações de dominação do capitalismo contemporâneo. O problema em transformar o conhecimento objetificado, no entanto, ocorre precisamente no ponto onde as críticas parecem completas. Suspender pressupostos disciplinares, como aqueles da sociologia, e substituí-los por pontos de vista alternativos, é, muitas vezes, difícil para aqueles considerados críveis dentro dos pressupostos da disciplina, especialmente se a sua credibilidade é baseada no poder de suas críticas. Participar de uma disciplina requer aceitar suas premissas e argumentar como se elas fossem dadas, mesmo que muitas das suposições básicas sejam em si mesmas suspeitas. Uma perspectiva crítica transformadora, portanto, permanece geralmente indisponível aos praticantes de uma disciplina, porém, é mais prontamente aparente para aqueles que estão fora da disciplina e que possuem pontos de vista alternativos sobre a realidade social. Em algum momento, a fim de transformar o conhecimento, teóricos como Dorothy Smith saltam para fora dos quadros dominantes. Esse processo envolve unir-se ao círculo interno a fim de criticar suas formas de conhecimento e, então, criar novas formas [de conhecimento] rejeitando o círculo e começando em um novo lugar. Espera-se que o melhor do que foi criado no e pelo círculo interno influencie a criação de conhecimento fora dos quadros dominantes. O trabalho de Dorothy Smith fornece uma poderosa crítica ao círculo interno da sociologia. Além disso, em sua busca por desenvolver uma sociologia para mulheres ou uma sociologia feminista do conhecimento, Smith faz importantes progressos na criação de uma sociologia que se mova para fora das premissas dominantes. No entanto, duas características de seu trabalho limitam sua eficácia ao fazer o salto para fora das estruturas interpretativas existentes. A primeira característica é a ausência 
Transformando o Círculo Interno: o Desafio de Dorothy Smith à Teoria Sociológica
Dra. Patricia Hill Collins [UMD - EUA] tradução: Ms. Raquel

Suely Cardoso da

Conceição [UNIFESP]

de pontos de vista alternativos sobre a realidade social desenvolvida por grupos subordinados. O foco de Smith nos "textos", no conhecimento da literatura e na sociologia, como um exemplo de conhecimento especializado do discurso acadêmico, ignora outros tipos de saberes que podem contrariar as tendências hegemônicas do conhecimento objetificado. Os saberes locais, por exemplo, como aqueles produzidos por grupos subordinados cujas ideias são suprimidas por grupos dominantes, podem fornecer uma base potente de resistência às ideias do grupo dominante (Collins, 1990; Scott, 1985). Smith descreve como suas experiências individuais enquanto mulher lhe proporcionaram uma perspectiva única, mas ela não desenvolve esse insight para evocar tradições de saberes locais produzidos por grupos historicamente marginalizados. Tais conhecimentos, frequentemente produzidos e compartilhados oralmente entre membros de comunidades específicas, são menos facilmente controlados por organizações burocráticas do que palavras escritas. "Pessoas de cor sempre teorizaram", sugere a feminista afro-americana e crítica literária Barbara Christian (1988), "mas em formas bastante diferentes da forma ocidental da lógica abstrata. E eu estou inclinada a dizer que nossa teorização (e eu intencionalmente uso o verbo em vez do substantivo) está, muitas vezes, em formas narrativas, nas teorias que nós criamos, em enigmas e provérbios, no jogar com a linguagem, porque as ideias dinâmicas, ao invés das ideias fixas, parecem mais do nosso gosto" (p. 68).

Os insights de Christian apontam para tradições alternativas que podem complementar a vasta análise de Smith de como a dominação opera por meio da organização do conhecimento. Essas tradições de conhecimentos locais, ou os pontos de vista autodefinidos de grupos subordinados, têm sido amplamente invisíveis para os intelectuais acadêmicos, como os sociólogos, porque os grupos subordinados frequentemente ocultam esse conhecimento. É mais provável que essas tradições sejam vistas e compreendidas por intelectuais acadêmicos em campos mais próximos da cultura oral e das tradições narrativas, por indivíduos cuja marginalização histórica dentro das disciplinas acadêmicas - sua posição outsider-within ${ }^{4}$ - promoveu sua invocação de conhecimentos locais como fontes de apoio, ou pelos chamados intelectuais "orgânicos", cuja posição fora das estruturas dominantes os fundamenta, mais firmemente, em visões de mundo alternativas. $\mathrm{O}$ fracasso dos intelectuais acadêmicos em investigar essas tradições não significa que tradições alternativas não existam ${ }^{5}$.

4 N.T.: O conceito outsider-within pode ser traduzido literalmente como "forasteiras de dentro", entretanto, por não expressar uma tradução exata sobre a problemática subjacente ao conceito, o termo será mantido no original.

5 A análise de James Scott das formas de resistência camponesa na Malásia fornece um convincente estudo de caso sobre a importância de os conhecimentos locais resistirem aos "textos" 
Transformando o Círculo Interno: o Desafio de Dorothy Smith à Teoria Sociológica
Dra. Patricia Hill Collins [UMD - EUA]

Quando explicamos a diversidade de experiências das pessoas, a diversidade entre mulheres e as experiências de pessoas de cor e de outros grupos historicamente marginalizados, a importância de saberes locais - de teorizar a partir de outras localizações que não os "textos" controladores de discurso dominante - entra em foco. Uma vez que Dorothy Smith subestima a diversidade criada por raça, gênero, classe, orientação sexual e idade, seu trabalho negligencia os conhecimentos produzidos por esses grupos, pois eles resistem ativamente ao conhecimento objetificado que justifica sua subordinação. Por exemplo, a ênfase de Smith no silêncio das mulheres e no esforço para criar uma linguagem para mulheres ignora as tradições preexistentes entre grupos de mulheres que possuem idiomas alternativos e desconsidera as visões de mundo que foram suprimidas. Mulheres afro-americanas, por exemplo, não têm estado em silêncio porque lhes falta linguagem. Em vez disso, elas foram silenciadas por não terem permissão de falar a linguagem que possuem, pelo menos na maioria dos espaços públicos (Collins, 1990). Tradições alternativas existem, porém, elas permanecem invisíveis e ininteligíveis às abordagens sociológicas existentes.

A análise de Smith dos usos do conhecimento na estruturação das relações de poder dentro do capitalismo contemporâneo seria fortalecida se ela explorasse como os saberes locais podem combater as tendências hegemônicas do conhecimento objetificado. Esse enfoque também poderia reinserir outra ideia principal do pensamento social marxista que Smith evoca, mas subestima, a saber, a natureza dialética de todas as relações sociais de dominação e resistência. Atualmente, grande parte do trabalho de Smith inclui uma noção de humanos como uma coleção de indivíduos, diferenciados, em primeiro lugar, por gênero e, em segundo lugar, por classe social. Essa abordagem perde a complexidade acerca de como raça, gênero, classe social, idade, orientação sexual e religião resultam em posições diferentes em relação a conhecimentos objetificados, e de como essa posição incentiva alguns grupos a desenvolverem, e outros grupos a suprimirem, conhecimentos locais alternativos, e a suprime, ainda, em outros. Reinserir noções de diversidade em análises de relações sociais pode revelar as variadas maneiras pelas quais as pessoas criam conhecimentos locais para combater o conhecimento objetificante, e, portanto, pode expor a dialética complexa de formar, e também de ser formado, pelas relações sociais.

O trabalho de Smith sobre a organização social do conhecimento objetificado revela muito sobre a construção social da dominação. Ironicamente, no

de dominação. Para uma discussão sobre a importância do conhecimento local, da tradição oral e de formas alternativas de conhecimento no pensamento feminista afrocêntrico, ver Collins (1990), capítulo 5, "The Politics of Self-Definition", e capítulo 10, "Toward an Afrocentric Feminist Epistemology". 
Transformando o Círculo Interno: o Desafio de Dorothy Smith à Teoria Sociológica
Dra. Patricia Hill Collins [UMD - EUA] tradução: Ms. Raquel

Suely Cardoso da

Conceição [UNIFESP]

entanto, embora ela mesma não tenha enfatizado a resistência a tal dominação, sua insistência que comecemos a sociologia a partir das experiências vividas pelas pessoas fornece uma estrutura potencialmente eficaz para o estudo da resistência. Ao discutir a necessidade de tornar os mundos cotidianos o locus de uma problemática sociológica, ela afirma: "É necessariamente local - porque é assim que devemos ser - e necessariamente histórico" (1987, p. 89). Smith, no entanto, ainda não ampliou as implicações de sua própria abordagem para estudar como os conhecimentos locais produzidos por grupos com tradições historicamente identificáveis têm sido usados para resistir à dominação. Quando tais descobertas forem complementadas por atenção teórica e empírica, igualmente bem desenvolvidas, com vistas à construção social da resistência, organizada por meio de conhecimentos locais, será revelada uma peça importante de uma sociologia que empodera os indivíduos a resistirem à dominação.

A segunda dificuldade que Smith enfrenta ao saltar para fora das quadros do discurso dominante diz respeito à tensão entre a necessidade de criar uma sociologia emancipatória, que se recuse a apoiar relações de dominação, e a dificuldade de fazê-lo, enquanto se usa a linguagem e a visão de mundo implícita no círculo interno. O dilema de Dorothy Smith confronta todos nós que queremos transformar o círculo interno. "Nós aprendemos uma maneira de pensar sobre o mundo, uma maneira de conhecê-lo, que é reconhecível aos seus praticantes como uma forma sociológica de pensamento, e nós passamos a nos identificar como profissionais nesses termos. Dessa forma, o discurso organiza nossas relações sociais com aqueles que se tornam os objetos de nosso estudo", ela observa (1987, p. 73). É preciso, primeiro, aprender a linguagem do círculo interno a fim de compreender o que está sendo dito e ganhar credibilidade. No entanto, assumir a linguagem do discurso dominante, mesmo usando a linguagem do conhecimento objetificado para criticar seus termos, une o intelectual às relações de dominação apoiadas pelo conhecimento objetificado.

Smith parece reconhecer esse dilema, mas ainda não encontrou uma saída. Considere, por exemplo, em seus primeiros trabalhos, a ênfase na "line of fault" , a disjunção real ou potencial entre a experiência e as formas nas quais a experiência é expressa socialmente (1987, p. 50). No caso de Smith, a disjunção era entre seu conhecimento cotidiano das experiências das mulheres e o conhecimento objetificado produzido por uma sociologia que reivindicava tornar essas experiências inteligíveis. Smith argumenta que a "consciência bifurcada",

6 N.T.: O termo "line of fault", que poderia ser traduzido, literalmente, como "linha de culpa/ linha de falha", refere-se, comumente, a falhas geológicas. Porém, não consideramos essa tradução adequada para a sua aplicação no texto. Assim, optamos por utilizá-lo no original. 
Transformando o Círculo Interno: o Desafio de Dorothy Smith à Teoria Sociológica
Dra. Patricia Hill Collins [UMD - EUA] tradução: Ms. Raquel

Suely Cardoso da

Conceição [UNIFESP]

produzida por ser tanto uma mulher quanto uma socióloga em uma disciplina dominada pelo masculino, produziu novos ângulos de visão sobre ambas, as experiências das mulheres e a sociologia. Smith inicialmente escreveu a partir de uma posição como sujeito e exigiu que mulheres, como um grupo, fossem tratadas como tal. Seu trabalho inicial demonstra o poder do conhecimento criado por alguém que se situa fora do discurso dominante e que possui conhecimento local, ou seja, conhecimento que cresce a partir das experiências das mulheres.

Contudo, Smith também reconheceu que, a longo prazo, permanecer na line offault deixa o círculo interno inalterado porque as regras do que constitui a sociologia permanecem intactas. Smith escolheu aderir às regras, fazer sociologia teórica de uma maneira que faça sentido aos membros do círculo interno. Seu trabalho é extremamente valioso ao desafiar as regras do método sociológico em seus próprios termos. Mas, aproximar-se do círculo interno significa que alguém participa das mesmas relações de dominação que Smith abomina. Sua afirmação de que "o discurso organiza nossas relações sociais com aqueles que se tornam os objetos de nosso estudo" (1987, p. 73) é igualmente aplicável à sua própria sociologia. Ironicamente, embora suas ideias forneçam novos insights sobre como o círculo interno pode ser transformado, seu discurso nunca pode ser verdadeiramente transformador porque está organizado na linguagem do círculo interno, essencialmente endereçada a seus membros.

Smith enfrenta um dilema difícil. Ironicamente, à medida que se obtém mais acesso e maior discernimento quanto aos funcionamentos do círculo interno, esse movimento para dentro do status limita o acesso aos conhecimentos locais e aos ângulos de visão especiais disponíveis para aqueles que estão fora do discurso dominante. Como a poeta lésbica afro-americana Audre Lorde (1984) explica, "as ferramentas do mestre nunca irão desmantelar a casa dele. Elas podem nos permitir vencê-lo temporariamente em seu próprio jogo, mas nunca nos permitirão provocar uma mudança genuína. E esse fato é ameaçador apenas para aquelas mulheres que ainda definem a casa do mestre como sua única fonte de apoio" (p. 112). Assim, o trabalho de Dorothy E. Smith nos possibilita percorrer uma grande distância no desafio de transformar a teoria sociológica. Mas, dadas as limitações de todos os estudiosos que pretendem desmantelar os círculos do mestre com as suas [do mestre] próprias ferramentas, eu suspeito que talvez não seja longe o suficiente. 
CHRISTIAN, Barbara. "The Race for Theory". Feminist Studies 14: 67-79, 1988.

COLLINS, Patricia Hill. Black Feminist Thought: Knowledge, Consciousness, and the Politics of Empowerment. New York: Unwin Hyman/Routledge, 1990.

LORDE, Audre. Sister Outsider. Trumansburg, NY: Crossing Press, 1984.

SCOTT, James C. Weapons of the Weak: Everyday Forms of Peasant Resistance. New Haven: Yale University Press, 1985.

SMITH, Dorothy E. The Everyday World as Problematic: A Feminist Sociology. Boston: Northeastern University Press, 1987.

. "Feminist Reflections on Political Economy". Studies in Political Economy 30: 37-59, 1989a.

"Sociological Theory: Methods of Writing Patriarchy", p. 34-64. Feminism and Sociological Theory, edited by Ruth Wallace. Newbury Park, CA: Sage, 1989b.

. The Conceptual Practices of Power: A Feminist Sociology of Knowledge. Boston: Northeastern University Press, 1990a.

. Texts, Facts, and Femininity: Exploring the Relations of Ruling. New York: Routledge, 1990b.

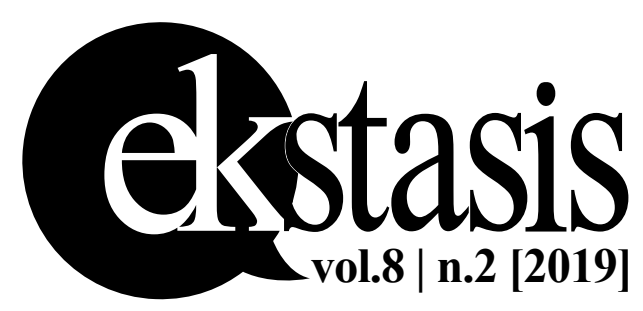

